\title{
IMPLEMENTASI SISTEM SIMULASI PENAMPILAN TATA SURYA BERBASIS 3D MENGGUNAKAN OPENGL
}

\author{
Mochammad Bagus Priyantono, Adam Achmad Rachmawan \\ Program Studi Teknik Informatika, Universitas Negeri Malang \\ Jl. Semarang No. 5 Lowokwaru, Malang \\ baguspriyantono.1805356estudents.um.ac.id, \\ adamrachmawan.1805356estudents.um.ac.id.
}

\begin{abstract}
The development of digital-based technology in the 4.0 industrial revolution era, making its application in facilitating various activities in various fields. One of them is in the process of learning about space management. This study discusses the implementation of the solar system into 3-dimensional simulation using the Code Block IDE and using the OpenGL library. The results of this study are expected to help improve the ability of a person in the regulation of the solar system by presenting objects through 3D-based animation using OpenGL media.
\end{abstract}

Keywords - Solar System, Simulation, OpenGL.

\begin{abstract}
Abstrak - Perkembangan teknologi berbasis digital pada era revolusi industri 4.0 ini, membuat penerapanya dalam memudahkan kegiatan dalam beberapa bidang semakin banyak digunakan. Salah satunya dalam membantu proses pembelajaran mengenai ruang tata ruang angkasa. Penelitian ini bertujuan untuk mengimplementasikan mengenai ruang tata surya ke dalam suatu simulasi bebabasis 3 dimensi dengan menggunakan IDE Code Block dan dengan menggunakan library OpenGL. Hasil dari penelitian ini diharapkan dapat membantu meningkatkan kemampuan terhadap seseorang dalam mempelajari tata surya dengan menghadirkan objek melalui implementasi animasi bebasis 3D dengan menggunakan media OpenGL.
\end{abstract}

Kata kunci - Tata Surya, Simulasi, OpenGL.

\section{PENDAHULUAN}

Pembelajaran mengenai Tata surya merupakan pembelajaran yang wajib dipelajari dibangku pendidikan. Adapun pengertian tata surya merupakan sekumpulan benda langit yang tersusun atas Matahari, delapan buah planet yang memiliki orbit berbentuk elips, serta komponen-komponen lainnya seperti asteroid, meteor, komet dan lainnya [1]. Namun pada umumnya pembelajaran mengenai tata surya yang diberikan pada saat SMA (Sekolah Menengah Atas) hanya terpaku dengan menggunakan teori saja. Sehingga dinilai kurang menarik dalam menambah pengetahuan mengenai tata surya. Sehingga diperlukan suatu teknologi yang dapat menghadirkan sebuah simulasi objek mengenai tata surya.

Dengan berkembangnya penerapan teknologi Informasi yang semakin pesat. Memungkin dibuatnya sebuah teknologi yang dapat membantu kegiatan manusia dalam segala bidang. Salah satunya dalam media pembelajaran. Seperti halnya pada penelitian Deddy Suhardiman yang membuat sebuah simulasi pergerakan dengan menggunakan openGL[2]. Adapun penelitian yang dilakukan Agung Slamet Riyadi yang memanipulasi objek segitiga dan segiempat dengan menggunakan openGL[3]. Dan pada penelitian Wahyudi Hasbi yang menerapkan openGL sebagai media pengajaran[4]. Sehingga dari beberapa penelitian terdahulu dapat diketahui bahwa penerapan teknologi dapat digunakan dalam mendukung beberapa kegiatan manusia.

Dari masalah dan beberapa penelitian yang telah di paparkan diatas, mendorong penulis dalam membuat sebuah penelitian yang menghadirkan sebuah implementasi objek berbasis 3D dalam sebuah sistem simulasi penampilan tata surya dengan menggunakan OpenGL dan IDE Code Block sehingga dapat membantu menunjang pelajaran tata surya atau konsep mengenai ruang angkasa pada pembelajaran SMA (Sekolah Menengah Atas). Adapun batasan masalah dalam peneltian ini adalah hanya dapat menggunakan sebuah kompiler yaitu IDE Code Block dan menggunakan sebuah library data yakni OpenGL

\section{A. Tata Surya}

Tata surya merupakan kumpulan benda langit yang tersusun atas sebuah bintang yang mana bernama matahari dan semua objek yang terikat oleh gaya gravitasinya. objek tersebut termasuk delapan buah planet yang sudah diketahui dengan orbit berbentuk 
elips, lima planet kerdil, seratus tujuh puluh tiga satelit alami yang telah diketahui dan jutaan benda langit [1].

\section{B. Objek Tiga Dimensi}

Objek tiga dimensi adalah sebuah objek yang memiliki Panjang, lebar, dan tinggi. Pada objek ini memiliki titik koordinat sumbu x sebagai bagian datar, titik koordinat sumbu y sebagai sebagai sumbu tegak, dan titik koordinat sumbu z sebagai sumbu lurus, agar hasil menjadi maksimal maka konfigurasi sudut $\mathrm{x}, \mathrm{y}, \mathrm{z}$ minimal 0 dan maksimal sebesar resolusi yang digunakan [5].

\section{OpenGL}

OpenGL merupakan spesifikasi standar yang mendefinisikan sebuah lintas bahasa, yang dapat menghasilkan grafis computer dua dimensi maupun tiga dimensi. Open GL dikembangkan oleh Silicon Graphics Inc (SGI) pada tahun 1992 dan secara luas digunakan dalam CAD, realitas maya, visualisasi ilmiah, visualisasi informasi, dan simulasi penerbangan [6]. .

\section{Bahasa pemrograman $\mathrm{C}++$}

$\mathrm{C}++$ merupakan Bahasa pemrograman yang merupakan perkembangan dari Bahasa C. Bahasa itu diturunkan dari bahasa sebelumnya yaitu bahasa B. bahasa tersebut dirancang sebagai bahasa pemrograman yang dijalankan pada sistem Unix, Untuk mendukung fitur-fitur pada $\mathrm{C}++$, dibangun efisiensi dan sistem support untuk pemrograman tingkat rendah (low level coding)[7].

\section{E. Media Pembelajaran}

media pembelajaran merupakan media yang dapat digunakan dalam menunjang kegiatan pembelajaran, hal ini bertujuan untuk menyampaikan isi materi mengenai pembelajaran dari guru maupun dari materi yang hendak dipelajari kepada penerima [8].

\section{F. IDE CODE BLOCK}

Code::Blocks adalah IDE (Integrated Development Environment), yakni lingkungan development terintegrasi untuk pemrograman bahasa $\mathrm{C} / \mathrm{C}++$ dan Fortran. Berbagai macam free Compiler tersedia di sana, seperti halnya Borland $\mathrm{C}++$ Compiler dan sifatnya gratis[9].

Compiler ini dapat diinstal di berbagai sistem operasi tanpa menghilangkan fitur fitur utamanya [9].

\section{METODE PENELITIAN}

\section{A. Kerangka Penelitian}

Metode penelitian yang penulis gunakan untuk pengembangan perangkat lunaknya yaitu menggunakan model air terjun (waterfall). model ini merupakan pendekatan perangkat lunak secara terurut yang dimulai dari Study Literature, Pengembangan Sistem ,
Implementasi dan pengujian sistem [10]. Seperti ditampilkan pada gambar 1 berikut ini.

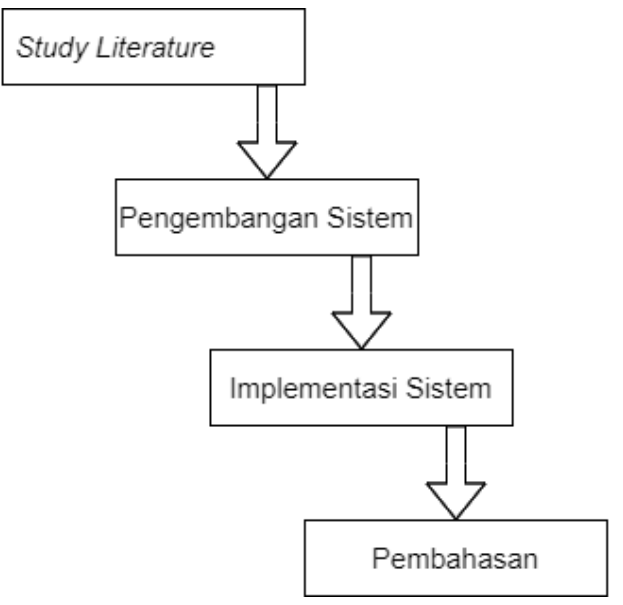

Gambar 1 Kerangka Penelitian

\section{B. Pengembangan sistem.}

Pada tahap ini dilakukan pengembangan sistem dengan dilakukan pencarian data mengenai jenis jenis objek tata surya meliputi ukuran, gerak revolusi dan rotasi, serta posisinya. Adapun pencari data ini dilakukan dengan study literature yang dilakukan secara online. Adapun data yang telah ditemukan nantinya akan di implementasikan pada objek 3 Dimensi menggunkan tools IDE Code Block. Selain melakukan pencarian data mengenai objek, pada tahap ini juga melakukan pencarian terhadap komponen-komponen yang diperlukan terkait pembuatan sistem simulasi tata surya berbasis 3 Dimensi ini. Adapun analisis kebutuhan sistem yang diperlukan yakni

1. Sistem Operasi Windows 10.

2. IDE::CodeBlock.

3. Library OpenGL.

4. RAM Minimum 4 GB.

5. VGA

\section{Alur Sistem}

Pembuatan sistem simulasi tata surya berbasis tiga dimensi ini menggunakan bahasa pemrograman $\mathrm{C}++$, dengan library glut.h dari openGL yang digunakan untuk mendefinisikan objek tiga dimensi maupun objek dua dimensi, dan juga dapat mendefinisikan interaksi dan animasi yang dari user. Dalam pembuatan animasi ini. Menggunakan IDE::Code Block yang merupakan alat untuk development berbagai macam program salah satunya pembuatan animasi dengan bantuan library glut.h dari openGL yang berbasis dari bahasa pemrograman $\mathrm{C}++$. Dalam pembuatan animasi ini, terdapat flowchart yang dapat menjelaskan alur dari program ini, seperti halnya pada gambar 1 . 


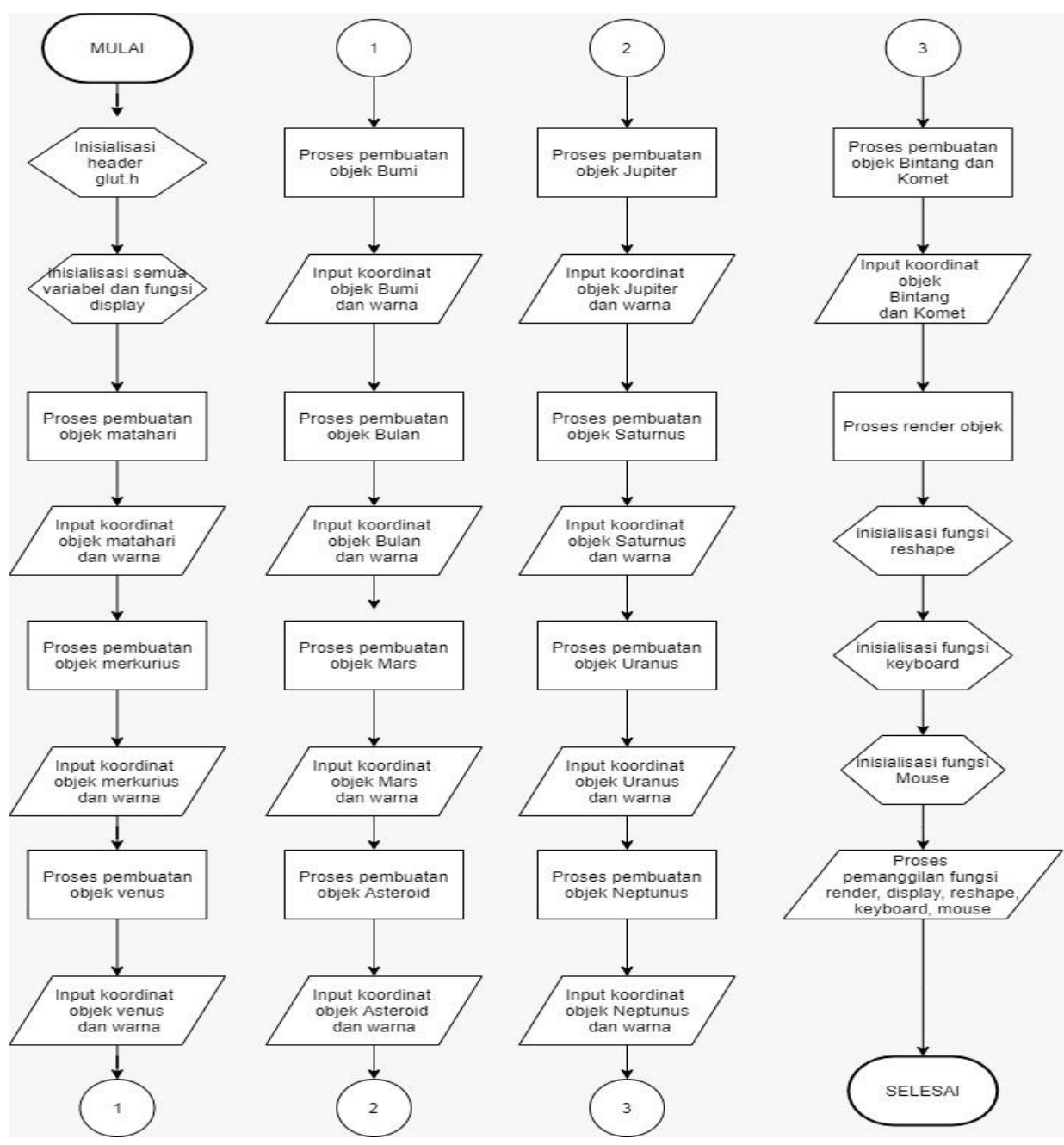

Gambar 2 FlowChart Sistem

\section{HASIL DAN PEMBAHASAN}

\section{A. Implementasi}

Pada tahap ini adalah menerapkan semua proses yang telah dibahas pada pembahasan sebelumnya. Seperti halnya melakukan pengkodean pada IDE::Code Block dengan menggunakan Library OpenGL dengan memasukan fungsi-fungsi bawaan yang telah disediakan. Seperti halnya pada gambar 3 berikut ini.

\section{1 \#include 〈windows.h〉 \\ 2 \#include $\langle$ stdlib.h〉 \\ 3 \#include $\langle\mathrm{GL} /$ glut.h $\rangle$ \\ 4 \#include $\langle$ math. $\mathrm{h}\rangle$}

Gambar 3. Pengkodingan menggunakan OpenGL

\section{B. Hasil}

Adapun pada tahap ini adalah menampilkan hasil yang telah diperoleh dari implementasi yang telah dilakukan. Pada hasil ini dapat pula menggerakan objek dengan menggunakan interaksi dengan perangkat komputer yaitu Keyboard dan Mouse. Interaksi tersebut dapat berupa pergerakan pemindahan posisi koordinat ataupun dapat melihat lebih dekat atau jauh. Adapun tampilan awal seperti pada gambar 4 berikut ini

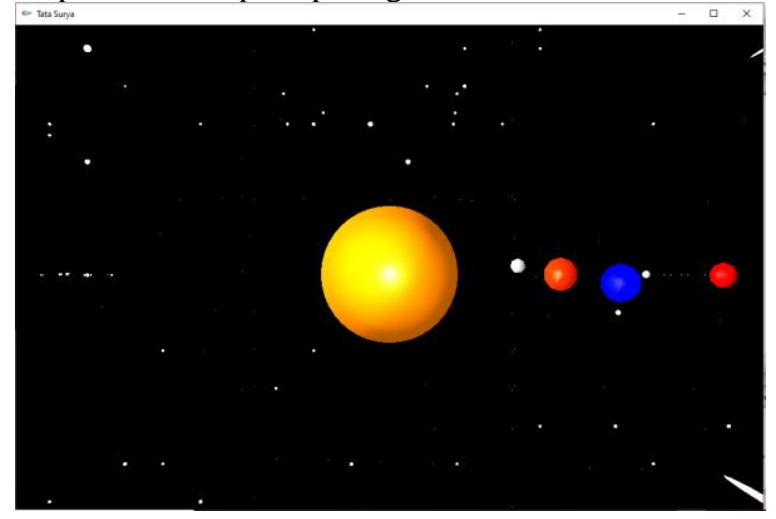

Gambar 4. Tampilan Awal

Pada Tampilan awal tersbut menampilkan keadaan tata surya dengan terdapat objek yang terlihat pada tampilan 
awal ini yakni matahari, merkurius, venus, bumi, bulan, dan mars. Objek - objek akan muncul di koordinat yang telah ditentukan pada saat pengkodean dan tidak ada objek yang berpindah tempat sebelum dilakukan interaksi. Adapaun proses saat melakukan interaksi menggunakan suatu fungsi dari Library OpenGL yakni fungsi glRotate() dan glTranslate() agar objek dapat berpindah posisi. Adapun jika interaksi dilakukan akan tampak seperti pada gambar 5, 6, 7, 8 dan9 berikut ini

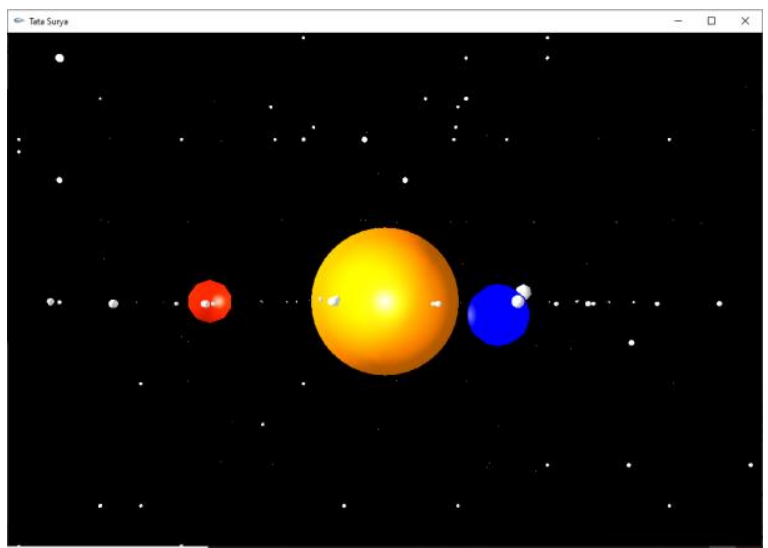

Gambar 5. Proses Interaksi dengan menggerakan semua objek tata surya dilihat dari sisi samping.

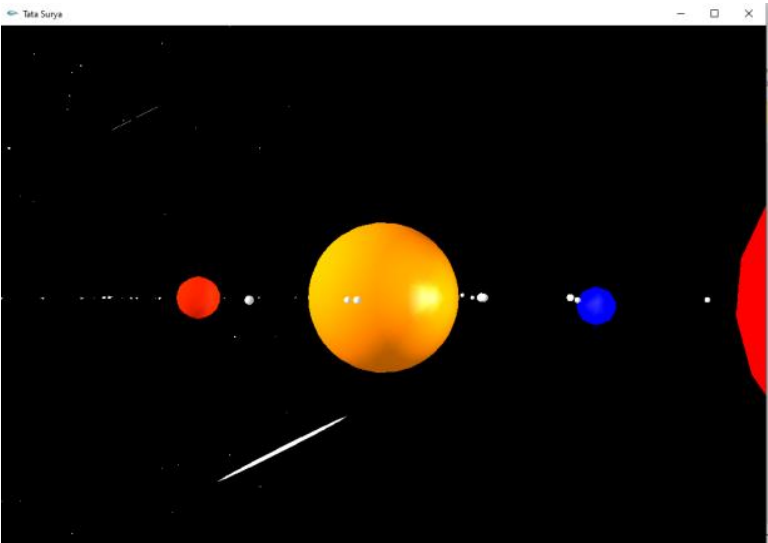

Gambar 6. Proses Interaksi dengan menggerakan semua objek tata surya dilihat dari sisi depan

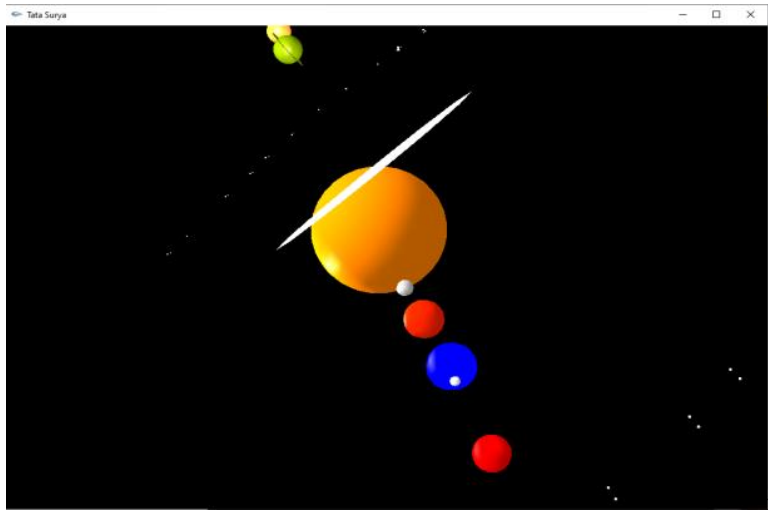

Gambar 7. Proses Interaksi dengan menggerakan semua objek tata surya dilihat dari sisi atas

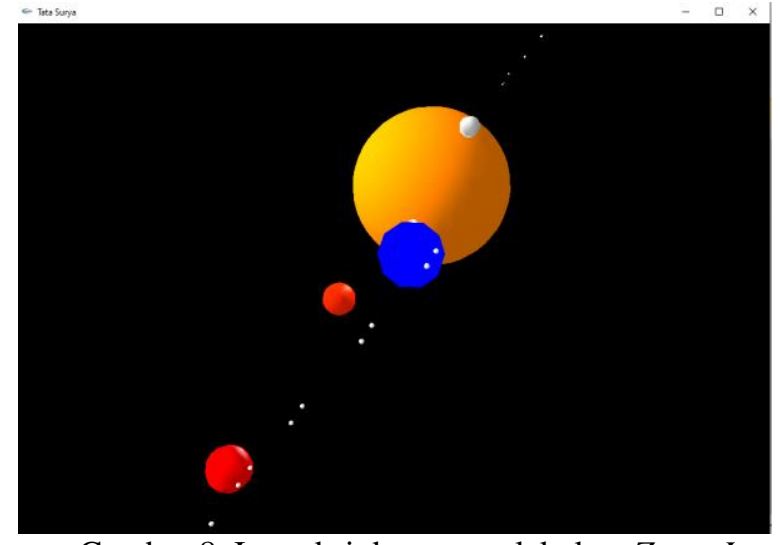

Gambar 8. Interaksi dengan melakukan Zoom In

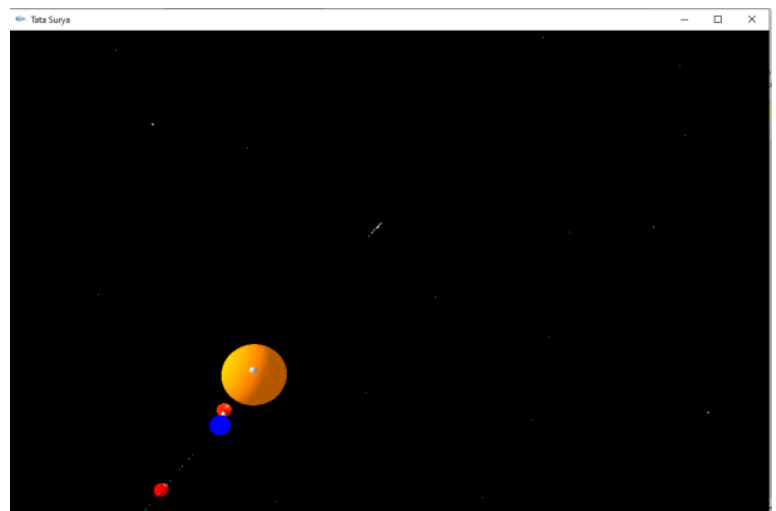

Gambar 9. Interaksi dengan melakukan Zoom Out

Pada tampilan gambar diatas interaksi merupakan interaksi pada tampilan sistem dengan menggunakan Keyboard ataupun Mouse. Adapaun pada gambar diatas yakni dapat melakukan sebuah interaksi dengan menggeser posisi koordinat. Adapaun tampilan dapat digeser dengan merubah sumbu koordinat layar yakni menggeser sumbu $\mathrm{x}$ pada pergeseran tampilan dari samping. Untuk pergesaran tampilan dari depan yakni dengan menggeser sumbu y dan untuk pergeseran tampilan dari atas dengan menggunakan sumbu $\mathrm{Z}$. Selanjutnya untuk memperbesar atau memperkecil tampilan (Zoom in, Zoom out) yakni dengan menggunakan interaksi dengan mouse. Interaksi yang digunakan dengan menggunakan keyboard yakni dengan menggunakan fungsi glutKeyboardFunc(), untuk interaksi menggunakan mouse yakni dengan menggunakan fungsi glutMouseFunc().

Pada program ini bila program diperbesar / fullscreen maka objek - objek tidak mengalami perubahan bentuk dan proporsi objek tetap. Untuk melakukan hal tersebut menggunakan fungsi glutReshapeFunc(). Agar koordinat objek dapat diperbarui dan objek dimuat kembali dapat menggunakan fungsi glutPostRedisplay().

\section{Pembahasan}

Dengan dibuatnya sistem yang mensimulasikan mengenai objek tata surya berbasis 3 dimensi ini tentunya dapat menjadi sebuah media pembelajaran 
bagi para pelajar ataupun seseorang yang mengkagumi dunia antariksa. Pada sistem ini menampilkan segala objek di tata surya dengan berdasarkan study literature sehingga dapat lebih memahami mengenai konsep ataupun letak, perputaran mengenai tata surya. Tidak hanya itu tampilan pada sistem ini dapat digeser ataupun diperbesar atau diperkecil sehingga memungkinkan pengguna dapat melihat objek dengan dekat.

\section{KESIMPULAN}

Dari proses yang telah dibahas diatas dapat disimpulkan bahwa sistem simulasi ini tentunya sangat membantu dalam mempelajari tata surya. Karena dengan menggunakan sistem ini tentunya dapat menambah pemahaman mengenai urutan objek, letak objek serta perputaran objek. Adapun sistem ini dibuat menggunakan bahasa pemrograman $\mathrm{C}++$ yang mudah dipahami serta diterapkan. Selain itu pada pembuatan sistem ini juga menggunakan Library OpenGL. Dikarenakan penggunaanya yang open source dan dapat membuat sebuah objek 3 dimensi dengan terdapat fungsi - fungsi mengenai merotasi, merubah koordinat objek serta menerapkan interaksi dengan perangkat Keyboard dan Mouse. Sehingga penulis berharap agar sistem ini dapat digunakan pada pembelajaran tata surya.

Adapun penelitian ini masih harus dikembangkan lagi pada penelitian berikutnya. Yakni memungkinkan dapat digunakan dengan menggunakan teknologi AR (Augmented Reality). ataupun teknologi sejenisnya.

\section{DAFTAR PUSTAKA}

[1]. Wikipedia. Tata Surya. (https://id.wikipedia.org/wiki/ Tata_Surya).(Online).Diakses tanggal 26 April 2020

[2]. D. Suhardiman, et al. Pembuatan Simulasi Pergerakan Objek 3D (Tiga Dimensi) Menggunakan OpenGL. Jurnal Teknik Elektro dan Komputer. Vol 1 No 2. 2012.

[3]. A. S. Riyadi, IMPLEMENTASI OPEN GL32 UNTUK MEMANIPULASI GAMBAR SEGITIGA DAN SEGIEMPAT. Jurnal KomTekInfo Fakultas Ilmu Komputer, Volume 1, No. 1, Juni 2014.

[4]. S. W. Habsy, Aplikasi Pengembangan 3 Dimensi Sebagai Media Pengajaran. KOMPUTASI. Vol 4. No 7. 2007

[5]. Lintas Materi. Objek 3 dimensi, (https://www.lintas materi.com/2016/05/objek3dimensi.html? $\mathrm{m}=1)$.(Online). Diakses tanggal 27 April 2020

[6]. Wikipedia.

OpenGL. (https://id.wikipedia.org/wiki /OpenGL).(Online).Diakses tanggal 26 April 2020 .
[7]. Wikipedia. $C++$. (https://id.wikipedia.org/wiki/C\%2B \%2B).(Online). Diakses tanggal 26 April 2020.

[8]. J. D. Latuheru, Media Pembelajaran Dalam Proses Belajar-Mengajar Masa Kini. Jakarta: Departemen Pendidikan dan Kebudayaan, 1988.

[9]. Saptaji.com Mengenal Code Blocks, Free Cross Platform Ide For $\mathrm{C} / \mathrm{C}++/$ Fortran (http://saptaji.com/2015/07/12/ mengenal-codeblocks-free-cross-platform-ide-forccfor tran/).(Online).Diakses tanggal 26 April 2020

[10]. Rosa dan Shalahuddin M. Terstruktur dan Berorientasi Objek. Bandung: Modula, 2011. 